Journal of Engineering Science and Technology Review 7 (5) (2014) 5-8

Special Issue on Simulation of Manufacturing Technologies
JOURNAL OF

Engineering Science and

Technology Review

Conference Article

www.jestr.org

\title{
The Investigation of the Effect of Micro-Arc Oxidation Modes on the Adhesion Strength of Coatings
}

\author{
N.Yu. Dudareva*, R.V. Kalschikov, I.A. Butusov, R.R. Grin, I.V. Alexandrov and F.F. Musin \\ Ufa State Aviation Technical University, Ufa, Russian Federation
}

Received 10 September 2014; Accepted 20 September 2014

\begin{abstract}
The paper presents the results of studies of the properties of hardened surface layers formed by micro-arc oxidation on the workpiece surfaces of aluminum alloy Al-12Si-Mg-Cu-Ni. The authors attempted to determine the influence of micro-arc oxidation modes on the properties of the modified layers. Investigation of the adhesion strength of the surface layers formed at different concentrations of electrolyte components and analysis of the change in coatings adhesion characteristics after thermal cycling were presented.
\end{abstract}

Keywords: microarc oxidation, adhesion strength, surface

\section{Introduction}

The micro-arc oxidation (MAO) method became widespread for the hardening of valve metals such as $\mathrm{Al}, \mathrm{Ti}, \mathrm{Zr}, \mathrm{Mn}$ among others. This technology is frequently used for surface hardening of aluminum alloys parts where the oxide layers with high mechanical properties can be obtained [1-3]. The MAO method is widely used in engineering to improve the wear resistance of parts. However, this technology can have great prospects for obtaining thermal protective surface layers, which is especially important for the pistons of the internal combustion engines (ICE).

Thermal protective coatings have two significant drawbacks: low heat resistance and poor adhesion strength on piston aluminum alloys. Heat resistance of coatings can be characterized by the strength of their adhesion to the substrate during the repeated exposure to temperature loads, and it depends on the structure, phase composition and porosity of coatings. The heat resistance is also affected by the geometry of the parts, the rate of heating and cooling of the components and the difference in coefficients of thermal expansion of the metal substrate and coating [4].

Using MAO for developing the thermal protective layer on the high-silicon piston aluminum alloys is relevant, but has not been studied in depth[5]. It is known that the quality of the MAO layer is strongly influenced by process conditions [6], [7]. However, in scientific literature there is almost no information concerning the thermal stability of the MAO layer, which is the aim of this work to study the effect of MAO modes on thermal and adhesive strength of the surface layer, using samples of high-silicon aluminum alloy.

\footnotetext{
*E-mail address: natalia_id@mail.ru

ISSN: 1791-2377 (C) 2014 Kavala Institute of Technology. All rights reserved.
}

\section{Experiments}

The following micro-arc oxidation process parameters affect strongly the properties of the MAO-layer the concentration of the liquid glass $-\mathrm{C}_{\mathrm{lg}}, \mathrm{g} / \mathrm{l}$; the concentration of potassium hydroxide $-C_{\mathrm{KOH}}, \mathrm{g} / 1$ in electrolyte and capacity of the capacitor of the MAO setting - C, microfarads. A fractional factorial experiment has been designed for this research [8].

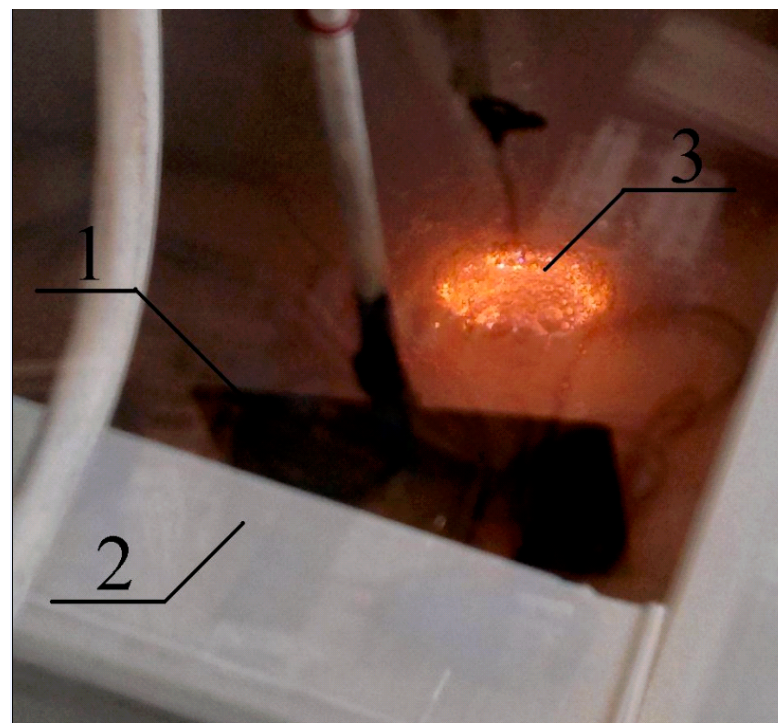

Fig. 1. The coating process: 1 - the electrode, 2 - the bath with electrolyte, 3 - the sample

Tests have been carried out with laboratory samples made of aluminum alloy Al-12Si-Mg-Cu-Ni (OST 19201490). The samples were disk shaped with diameter of $64 \mathrm{~mm}$ and thickness of $5 \mathrm{~mm}$. The working surface of the samples has been treated by MAO in five different modes. The treatment time was 3 hours. The concentration of liquid 
glass $\left(\mathrm{C}_{\mathrm{lg}}\right)$ changed in the range from 1.5 to $3.5 \mathrm{~g} / \mathrm{l}$, depending on the mode. The concentration of potassium hydroxide $\left(\mathrm{C}_{\mathrm{KOH}}\right)$ changed in the range from 1.5 to $3.5 \mathrm{~g} / 1$ and the capacity of the capacitor changed from 200 to 400 microfarad. The sample during the MAO process is shown in Fig. 1.

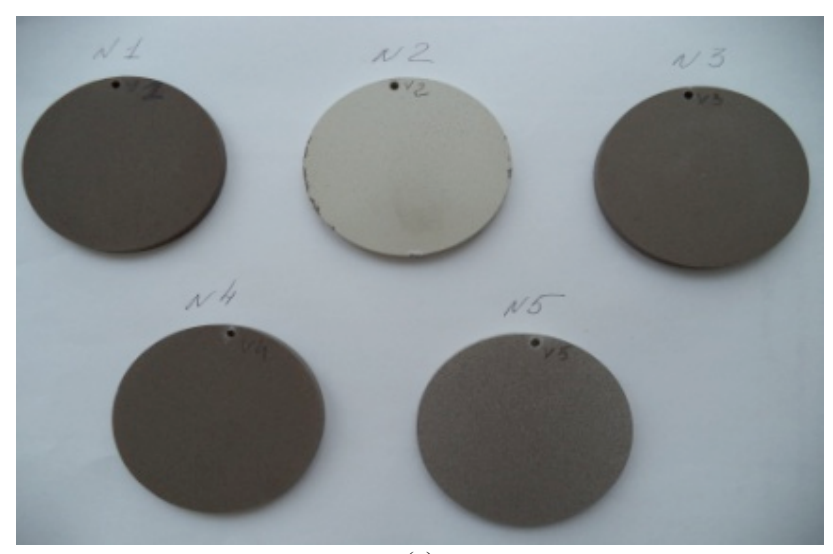

(a)

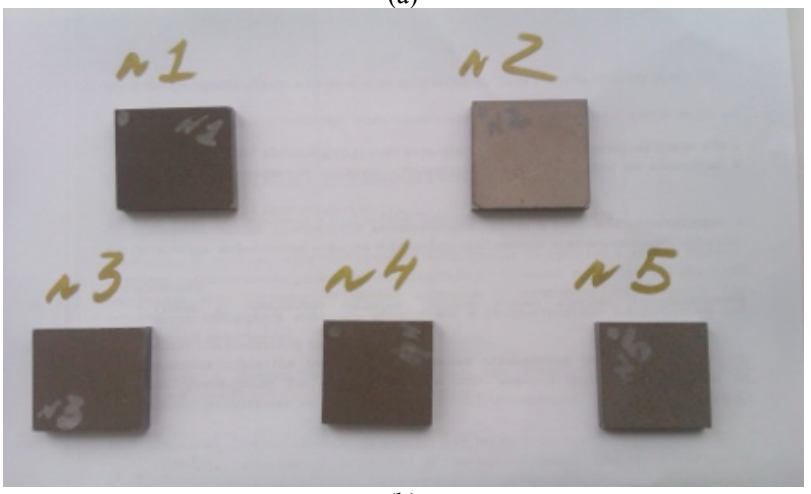

(b)

Fig. 2. Samples for testing the adhesive strength and heat resistance: a) initial samples after MAO; b) split samples

MAO-layers of different quality have been formed as a result (Fig. 2a). Then the samples have been cut into pieces for thermal cycling (TC) and scratch tests (Fig. 2b). The surface of the MAO layer has been ground on all the samples to achieve maximum hardness before testing. The MAO-layer thickness has been measured with a thickness meter TT-210 (Table 1) both initially and after thermal cycling. The microhardness of coatings has been measured on transverse sections using Struers Duramin equipment, with a load of $0.1 \mathrm{~kg}$, and the application time was $-10 \mathrm{~s}$. A Vickers diamond pyramid has been used as the indenter (Table 1).

Table 1. Thickness and microhardness of MAO-layers

\begin{tabular}{|c|c|c|c|c|c|}
\hline Parameter & 1 & 2 & 3 & 4 & 5 \\
\hline $\begin{array}{l}\text { The thickness of the } \\
\text { MAO layer, } \mu \mathrm{m} \\
\text { - after thermal cycling } \\
\text { - before thermal } \\
\text { cycling }\end{array}$ & $\begin{array}{l}46 \\
44\end{array}$ & $\begin{array}{l}111 \\
110\end{array}$ & 42 & 45 & $\begin{array}{l}50 \\
49\end{array}$ \\
\hline $\begin{array}{l}\text { Microhardness of } \\
\text { MAO-layer, GPa } \\
\text { - } \max \end{array}$ & 8.0 & 11.2 & 8.5 & 6.8 & 11.0 \\
\hline - average & 6.1 & 7.4 & 6.0 & 5.7 & 7.4 \\
\hline
\end{tabular}

The following methodology has been used for the thermal stability test of MAO-coatings: the samples have been placed in a Nabertherm furnace for 30 minutes at a temperature of $400{ }^{\circ} \mathrm{C}$ followed by cooling in water for 2 minutes. The total number of cycles has been 150. The research of MAO-layers adhesion strength was carried out every 30 cycles. Test of adhesion strength has been conducted with a "CSM MICROSCRATCH TESTER» using a Rockwell diamond indenter with a tip radius of 200 microns. Path length of the indenter was $5 \mathrm{~mm}$ during testing, the load applied to the indenter was increased from 0.03 to $30.00 \mathrm{~N}$ and the indenter displacement rate was 5 $\mathrm{mm} / \mathrm{min}$. The critical loads at which the first disturbance areas of the modified layer appears $\left(\mathrm{L}_{\mathrm{cl}}\right)$ and in which the MAO layer is destroyed $\left(\mathrm{L}_{\mathrm{c} 2}\right)$ have been measured. It has been done according to the results of investigation by comparing the fracture pattern, the depth of penetration of the indenter and the level of the acoustic emission. The tension on the indenter has been calculated by:

$\sigma_{\text {ind }}=\frac{L_{c}}{\pi} P_{d}\left(2 R_{\text {ind }}-P_{d}\right)$

where, $R_{\text {ind }}$ - the radius of the indenter (200 microns); $P_{d}$ - the depth of indenter penetration.

\section{Results and Discussion}

Test results for each sample are presented in Table 2, which contains the critical loads and tensions applied to the indenter at the beginning and after 150 thermal cycles.

Regression equations were compiled on the basis of the results presented in Table 2 . These equations allow the determination of the effect of MAO process parameters on the value of any stresses developed during indentation, which characterize the adhesive and cohesive properties of the developed MAO layers:

$$
\begin{array}{r}
\sigma_{\text {ind } 1}=-887.74-588.5 \cdot C_{K O H}+189.5 \cdot C_{K O H}^{2}+ \\
+281.6 \cdot \mathrm{C}_{\mathrm{lg}}+3.57 C \\
\sigma_{\text {ind } 2}=-622.76-738.6 \cdot C_{K O H}+219.2 \cdot C_{K O H}^{2}+ \\
+266.0 \cdot \mathrm{C}_{\mathrm{lg}}+3.45 C \\
\sigma_{\text {ind1 }}=-1050.48+141.5 \cdot C_{K O H}+21.6 \cdot C_{K O H}^{2}+ \\
+236.6 \cdot \mathrm{C}_{\mathrm{lg}}+2.04 C \\
\sigma_{\text {ind2' }}=313.87-1119.0 \cdot C_{K O H}+268.9 \cdot C_{K O H}^{2}+ \\
+233.6 \cdot \mathrm{C}_{\mathrm{lg}}+2.10 C
\end{array}
$$

where $\sigma_{\text {indl }}$ is the first critical stress before thermal cycling (there is a breakdown of the layer) $\mathrm{MPa} ; \sigma_{\text {ind2 }}$ is the second critical stress before thermal cycling (there is a destruction of the layer) $\mathrm{MPa} ; \sigma_{\text {indl }}$ is the first critical stress after thermal cycling, $\mathrm{MPa} ; \sigma_{\text {ind2 }}$ is the second critical stress after thermal cycling, $\mathrm{MPa} ; C_{K O H}-$ is $\mathrm{KOH}$ electrolyte concentration, $\mathrm{g} / \mathrm{l} ; \mathrm{C}_{\mathrm{lg}}$ is liquid glass $(\mathrm{Na} 2 \mathrm{SiO} 3)$ 
Table 2. Critical loads and tensions on the indenter at the beginning and after 150 thermal cycles.

\begin{tabular}{|c|c|c|c|c|c|c|c|c|}
\hline \multirow[b]{3}{*}{ № } & \multicolumn{4}{|c|}{ Initial state } & \multicolumn{4}{|c|}{150 thermal cycles } \\
\hline & \multicolumn{2}{|c|}{ Lc, $N$} & \multicolumn{2}{|c|}{ бind, $\mathrm{MPa}$} & \multicolumn{2}{|c|}{ Lc, $N$} & \multicolumn{2}{|c|}{ бind, $\mathrm{MPa}$} \\
\hline & Lc1 & Lc2 & oind1 & oind2 & Lc1' & Lc2' & oind1' & бind 2 ' \\
\hline 1 & 19.0 & 26.0 & 506 & 541 & 19.5 & 26.5 & 380 & 433 \\
\hline 2 & \multicolumn{2}{|c|}{29.5} & \multicolumn{2}{|c|}{$1787^{*}$} & \multicolumn{2}{|c|}{29.7} & \multicolumn{2}{|c|}{$1351 *$} \\
\hline 3 & 22.0 & 26.5 & 355 & 383 & 11.9 & 20.1 & 445 & 479 \\
\hline 4 & 23.0 & 27.6 & 511 & 566 & 22.2 & 25.6 & 471 & 463 \\
\hline 5 & \multicolumn{2}{|c|}{28.8} & \multicolumn{2}{|c|}{$601 *$} & 21.8 & 25.4 & 640 & 413 \\
\hline
\end{tabular}

Note: *there was no destruction of coating with scratch test

concentration in the electrolyte, $\mathrm{g} / \mathrm{l} ; \mathrm{C}$ is the capacity of the capacitor of MAO setting/installation, microfarad.

The analysis of the destruction areas suggests that the destruction of the MAO layer during the scratch test takes place by transverse cracking and accumulation of cracks as the load increases and it does not depend on the number of thermal cycles. This shows the predominance of a cohesive destruction type. There is no exfoliation and extensive chipping, which are typical for the adhesive type (Fig. 3).

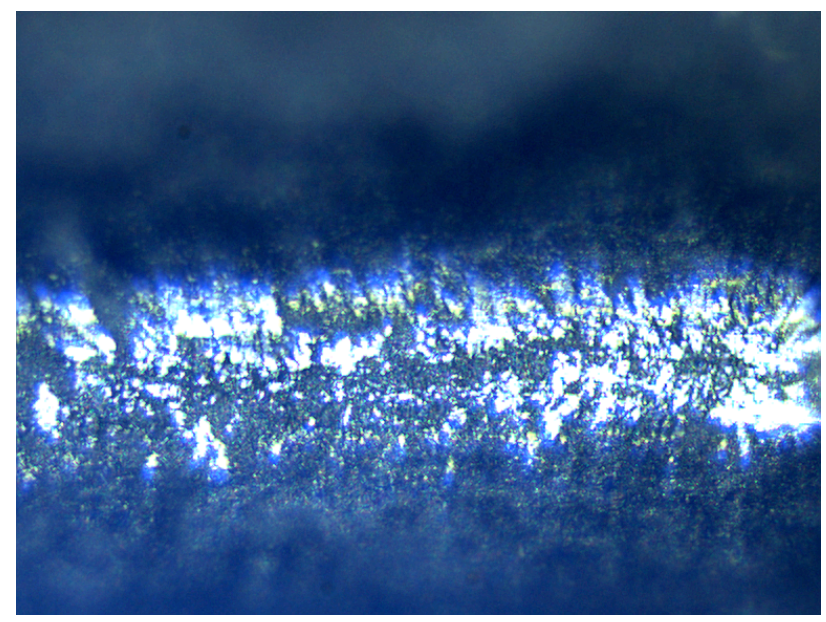

Fig. 3. Destruction area of MAO layer during the scratch test

The analysis of Table 2 shows that samples, treated in modes 1,3 and 4 are characterized by similar values of adhesion strength and have lower values for this parameter only to the MAO layers developed with modes 2 and 5 . Moreover, the scratch test has not identified the true values of adhesion strength for samples 2 and 5, as the maximum load $(30 \mathrm{~N})$ did not reveal any discontinuities of the MAO layer.

Using equations (1), (2), (3) and (4) it can be shown that the first and second critical stresses are almost equally depending on the concentration of $\mathrm{KOH}, \mathrm{Na} 2 \mathrm{SiO} 3$ and the capacity of the MAO installation. And their increase frequently associates with a growth in adhesion strength. This can be explained by the fact that potassium hydroxide, liquid glass and installation capacity contribute to the developement of MAO-layers with high thickness and microhardness during MAO-processing, which leads to their high adhesive strength.

The analysis of the data in Table 2 allows us to observe that there is a decrease of the adhesion strength of the MAOlayer after the thermal cycling for all the samples, except for samples treated with mode 3 (Table 2). There is an increase of the critical stress after thermal cycling for this sample. This effect may be due to changes in the MAO - layer after the thermal cycling, which led to the decrease in the depth of penetration of the indenter. The depth was $45 \ldots 50$ microns before thermal cycling and it became $28 . .35$ microns after thermal cycling, which increased critical stresses.

Thus, the maximum adhesion strength and the heat resistance are observed in MAO-layers obtained by the modes with the highest concentration of electrolytes and the highest current density. These conditions increase the intensity of the MAO-layer development and are characterized by maximum thickness, adhesion strength and heat resistance.

\section{Conclusions}

After having analyzed the results one can state the following:

1. The MAO modes have a significant effect on thickness, heat resistance and adhesion strength of the modified layers. The maximum values of the controlled parameters of the MAO-layer can be observed on the sample, treated by the second mode. This sample has an average thickness of 114 micrometers. The sample 2 preserved the integrity of the MAO-layer after the thermal multi-cycle tests with periodic measurement of the adhesion strength of the MAO- layer.

2. The increase of the concentration of liquid glass $\left(\mathrm{C}_{\mathrm{lg}}\right)$, potassium hydroxide $\left(\mathrm{C}_{\mathrm{KOH}}\right)$ and capacitors capacity (C) leads to an increase in thickness, heat resistance and adhesion strength of the modified layer formed by MAO.

\section{Acknowledgement}

This work is financially supported from the Ministry of Education and Science of the Russian Federation within the framework of the design part of the state task №11.2540.2014/K educational organization of higher education. 
N.Yu. Dudareva, R.V. Kalschikov, I.A. Butusov, R.R. Grin, I.V. Alexandrov and F.F. Musin /Journal of Engineering Science and Technology Review 7 (5) (2014) 5 - 8

\section{References}

[1] V.P. Alekhin, V.A. Feodorov, S.I. Bulichev, O.A. Tyurpenko, Physics and chemistry of materials processing, 5, p. 121-126, (1991).

[2] V.N. Malyshev, G.A. Markov, V.A. Feodorov, A.A. Petrosyan, O.P. Terleeva., Chemical and petroleum engineering, 1, P. $26-27$, (1984).

[3] I.V. Suminov [and others], Micro-arc oxidation: theory, technology, equipment, «Ekomet», Moscow, (2005).

[4] M.D. Nikitin, A.Ya. Kulik, N.I. Zaharov, Heat protection and wear resistant coatings of diesel parts, Engineering, Leningrad Department, (1977).

[5] B.V. Shandrov, E.M. Morozov, A.V. Zhukovski. Fundamentals of micro-arc oxidation technology: Study guide, «ID Alliance ", Moscow, (2008)

[6] N.Yu. Dudareva. Vestnik UGATU. 3, p. 217-222 (2013).

[7] P. I. Butyagin, E.V. Khokhryakov, A.I. Mamaev. Technologiya Metallov (Technology of metals). 1, p. 36- 39 (2005).

[8] Yu.P. Adler, Planning an experiment in finding the optimal conditions. Science, Moscow, (1976). 